\title{
EU Basic Safety Standards and European response to the Fukushima accident
}

\author{
A. JANSSENS
}

\begin{abstract}
The European Basic Safety Standards Directive (EU, 1996) contains a chapter on intervention, which, to a large extent, is dedicated to emergency planning and response, but without detailed requirements. A new Directive will consolidate all existing Directives and thus broaden the scope to all exposure situations and categories of exposure, including the protection of the environment. This new text follows the situation-based approach recommended by ICRP (ICRP, 2007). The requirements for emergency preparedness have been worked out in more detail, and the use of reference levels for emergency response is highlighted. The accident in Fukushima prompted reflection on the Euratom legal framework, including the Basic Safety Standards, the arrangements for the early exchange of information (ECURIE) and legislation on the nuclear safety of nuclear installations. A "stress test" of EU nuclear power plants has been undertaken, which includes on-site emergency response. The results of this exercise will allow the Commission to report, by the end of 2012, to the EP and the Council, and to propose new legislation as appropriate. This may extend to the harmonisation of off-site emergency response and communication arrangements among Member States. Meanwhile, an informal coordination mechanism is being set up with the Heads of European Radiation Protection Competent Authorities (HERCA). With regard to the legislation on maximum permitted levels in food, there will be further reflection on the consistency between the controls in place after Chernobyl and after Fukushima, as well as their consistency with the values for the placing on the market of food and feed in the $\mathrm{EU}$ in the event of a future accident.
\end{abstract}

Keywords: Nuclear/emergency/Europe/standards

European Commission, DG Energy, Radiation Protection Unit, EUFO 4157, L-2920 Luxembourg. 


\section{Euratom Basic Safety Standards (BSS)}

\subsection{Revision and consolidation of the BSS}

Under the Euratom Treaty (1957), the European Atomic Energy Community is required to lay down basic safety standards for the health protection of workers and members of the public.

The current Euratom Directive (96/29) which was adopted in 1996, following the publication of ICRP recommendations (ICRP Publication 60) in 1991, included requirements for emergency preparedness and response in a specific title IX: "Intervention". This title reflected the process-based distinction between practices and interventions advocated at that time by ICRP. This distinction also allowed the protection against enhanced exposure to natural radiation sources to be addressed, albeit under a heading "work activities", which was meant to be intermediate between practices and interventions. The term "intervention" covered both the management of lasting exposures resulting from past practices and work activities and the management of radiological emergencies. The 1996 Directive did not go into any detail, however, and merely required emergency preparedness to be provided for at national level, and encouraged the coordination of preparedness and response between neighbouring Member States.

In 2005 the Commission undertook a revision of the BSS together with a consolidation of five radiation protection Directives into a single document, as part of the overall policy of simplification of EU legislation. Relevant to emergency response is however just one Directive on informing the general public (EU, 1989). This revision benefitted from the new recommendations of ICRP (Publication 103) in 2007. The distinction between exposure situations rather than between practices and interventions facilitated a better structure of the standards, even though eventually the matrix was inverted and hence chapters by categories of exposures, occupational, medical, public and environmental, sequentially address all exposure situations (medical exposures only concern "planned" exposure situations, but accidental and unintended exposures are considered).

The new approach has permitted the full incorporation of natural radiation sources in the scope of the Directive, as well as the protection of the environment being addressed for the first time. The group of experts established under Article 31 Euratom drafted a text for the new BSS and adopted an Opinion in February 2010. Following an impact assessment of the new Directive the Commission adopted a draft proposal in September 2011 (EC, 2011). This draft is now awaiting the opinion of the Economic and Social Committee, and in spring 2012 a final proposal of the Commission will be submitted to the European Parliament for its opinion and to be Council for adoption.

\subsection{Emergency preparedness and response}

The new Directive will address emergency exposure situations in their own right, and require thorough emergency preparedness at national level. The requirements 
were inspired by publication 109 of ICRP (2009a). Very similar text has been drafted for the international BSS, adopted by the Board of Governors of IAEA in September 2011. A national "emergency management system" shall be "designed to be commensurate with the results of a threat assessment". The elements to be covered by the emergency management system are listed in a specific Annex. For the various types of emergencies identified by the threat assessment Member States shall ensure that emergency response plans are established in advance. The details to be covered by different (site-specific or type-specific) emergency plans are listed in another section of the same Annex. This includes the establishment of reference levels, optimised protection strategies for different postulated events and related scenarios, as well as predefined generic criteria and default triggers or operational criteria for particular protective measures.

The concept of "reference level", as defined by ICRP, has allowed the Directive to give indication of the acceptable range of exposures in an emergency exposure situation and of annual exposures in an existing exposure situation. The "acceptability" is expressed in terms of societal criteria in the same way as in Publication 103 (Tab. 5). While the establishment of appropriate reference levels is still a national responsibility, there is a powerful statement that in an emergency exposure situation these levels should be in the range 20 to $100 \mathrm{mSv}$. In the current Directive there is merely a sentence that "dose limits do not apply".

The Directive also strengthens the cooperation between Member States, and requires arrangements to be made with the emergency response organisations in a neighbouring country for facilities in the vicinity of a national border.

The protection of emergency workers is now well-embedded in the Chapter on occupational exposures. Responsibilities for protection, training and medical surveillance following an emergency exposure are addressed, and the conditions for application of reference levels are discussed. The Directive advocates that emergency workers should, in general, not be planned to undertake actions resulting in doses exceeding $50 \mathrm{mSv}$, except in specific cases identified in the national emergency plan.

\subsection{Living in contaminated areas}

Living in areas contaminated as a result of accidental releases of radioactive effluent or, in general, as a result of past practices, is now regarded as an existing exposure situation. The principles for its management are inspired by Publication 111 of ICRP (2009b), and their implementation relies very much on the direct involvement of stakeholders. This management is very similar to, and consistent with, other existing exposure situations such as radon in indoor air and building materials. It is a national responsibility to decide on the transition from an emergency to an existing exposure situation and on the application of the corresponding reference levels of annual affective dose. 


\section{The Fukushima accident}

The accident at the Fukushima-Daichi NPP's, following the unprecedented damage caused by an earthquake of magnitude 9 and a huge tsunami on the east coast of Japan, shed new light on the safety of nuclear installations and on the challenges for adequate response to protect the population in the short and the long term.

The accident happened at a time which was crucial for the adoption of the new Basic Safety Standards. Fortunately, the decision makers soon fully recognised the power of the new BSS in better addressing such a situation, so that the accident facilitated the decision rather than causing a delay.

The accident prompted further action, in particular a comprehensive review ("stress test") of the safety of nuclear installations and of the capabilities for onsite emergency response. The accident also prompted further reflection on the capacity of the EU and of Member States to respond to a nuclear emergency. This reflection concerns information exchange, response to remote accidents with implications on trade, communication, and the adequacy of the legislation on the placing on the market of food and feeding stuffs.

\subsection{Information exchange}

The EU has made adequate arrangements for the prompt exchange of information between national authorities on the basis of Council Decision 87/600/Euratom (EU, 1987a). In principle, this Decision foresees information exchange only "in case of situations requiring wide-spread countermeasures to be considered" at national level. Similarly, under the corresponding international Convention to which the EU has acceded (EC, 2005) the information exchange lacks a precise definition of the type of accidental situations that should be notified. The Commission's ECURIE arrangements (for the EU and some accession countries), agreed upon with national authorities, in practice have broadened the scope of application through "information messages" as opposed to the "alert messages" that are strictly required under the Council Decision. Nevertheless, the voluntary character of this arrangement is cause of uncertainty, despite qualitative guidance in the agreed manual for information exchange.

The ECURIE system is pushing information from Member States through the Commission to other Member States. For the potentially huge amount of data on levels of radioactivity in the environment it is better to pull the information from a network. For this purpose a data exchange platform was defined (EURDEP). Currently this network allows on-line access to all EU (and some neighbouring countries), data from continuous dose-rate monitoring stations. The Fukushima accident has highlighted the need to make progress on making available other environmental radioactivity monitoring data, in particular on levels of airborne activity concentrations. 


\subsection{Remote accidents}

For radiation protection experts it was immediately clear that the accident in Fukushima would have no consequences, significant from a radiological health perspective, in Europe. However, the understandable media attention which the accident received triggered a lot of questions on whether it was safe to travel to Japan, whether planes or ships approaching Japan could be contaminated or the crew exposed, whether goods or shipping containers would be contaminated etc. Authorities tried to respond to this demand in very different ways, looking into national response criteria that were not meant to be used for this purpose or into criteria for normal situations, for instance for transport of radioactive material. These approaches, together with the high uncertainty on the status of the affected reactors, caused a large disparity in national advice, both internationally and within the EU. This prompted a call for harmonisation of the response at EU level, in particular for issues relevant to trade. In the absence of a pre-established framework for this purpose, the Commission's response was limited to the overnight adoption of contamination criteria for ships and containers that were soon to enter European harbours. This non-binding guidance was transmitted to Member States through an ECURIE information message in April 2011. The choice of criteria proved later to be adequate (Opinion of the Article 31 Experts, given in June 2011), and there were in the first month only very few containers found to be contaminated. The absence of further cases of contamination prompted the Commission to lift this guidance in July 2011.

The Fukushima accident raised awareness of the need to discuss "soft" countermeasures, with little or no radiological significance, among national authorities. The NEA has undertaken a review of these countermeasures at international level, and within the EU there was an initiative of the Heads of European Radiation Protection Competent Authorities (HERCA), with full support of the EC, to set up a platform for such discussion to be activated right away in case of a future emergency. HERCA will also provide guidance for the response to remote accidents, and attempt to harmonise and coordinate national emergency response strategies.

\subsection{Communication}

The Fukushima accident also highlighted an important change in society, for instance since the time of Chernobyl, in the access to and dissemination of information. People in Europe watched the events in Japan not only through television and newspapers but also through internet and social networks. Inversely, citizens of Japan were well aware of the response in other parts of the world. Overreaction elsewhere sometimes provoked distrust of the Japanese information channels. It also proved to be very difficult to explain the rationale of radiation protection, the distinction between activity concentration and dose, the difference between normal acceptance criteria and those in case of an emergency etc. This represented a huge challenge for national sources of information and official spokesmen. The workload of information collection and dissemination soon came to saturation both in national institutes and in international bodies. The workload was further 
enhanced by solicitations from the press to authorities not only to explain decisions within their remit, but also to comment on other sources of information. A better definition of the responsibilities of different communication channels should be pursued; also better links between these channels, and possible ways for translating the information in understandable language should be explored and exercised.

\subsection{Food and feeding stuffs}

The wholesomeness of food is a primary concern among the population especially in those regions of the world where food is abundant and easily replaceable. Any contamination, including by radioactive substances, is therefore prone to be a very sensitive issue. From a radiation protection point of view the volume of the import of food from Japan in the EU is very small, and the levels of radioactivity in food harvested in Japan were moderate. Hence it was not judged appropriate to apply the maximum permitted levels laid down in Council Regulation 3954/87/ Euratom (EU, 1987b). These levels are meant to be applied in case of widespread contamination in or near Europe, and the Regulation does not distinguish between the placing on the market of imported food and of food grown in the EU.

However, there was strong public and political pressure to provide reassurance through controls of food imported from Japan. At first, Commission implementing regulations referred to the pre-established levels in Regulation 3954/87. When public opinion got aware that the permitted levels for Caesium in Japan (500 Bq/ $\mathrm{kg}$ ) were lower than those in the EU, there was pressure to control on the basis of the Japanese values. While this was defendable in terms of reciprocity, there were no radiation protection grounds for this decision, as confirmed by the Article 31 Experts in June 2011. People fail to understand that the permitted levels should be lower where the extent of contaminated food on the market is high, since it is not the activity concentration which defines a safe level but the accumulated annual exposure. The EU is now facing the risk that, if Japan would further lower its levels as a possible means for a return to normality, the same levels would be applied to the import in the EU from Japan, whereas the levels applying to import from third countries affected by the Chernobyl accident (EU, 2009) would remain the same $(600 \mathrm{~Bq} / \mathrm{kg})$. In addition, in case of a future accident in the EU, the Japanese levels could still apply or not yet be forgotten, and European consumers would request the same level of protection as was the case after the Fukushima accident, rather than the value laid down in Regulation 3954/87/Euratom $(1250 \mathrm{~Bq} / \mathrm{kg})$.

Regulation 3954/87/Euratom is currently under review in a recast procedure, also allowing for the implementing powers that can be entrusted to the Commission under the Treaty on the Functioning of the EU (2007). There will be further reflection on whether specific measures should be anticipated for the import of food from distant countries, and on the need to harmonise the levels and import conditions currently applied to food imported from the Chernobyl region and from Japan. 


\section{Conclusions}

The new Euratom Basic Safety Standards will offer a comprehensive framework for adequate and proportionate response to a radiological emergency. Whether this response should remain fully a national responsibility can be questioned however. On the one hand there is a need to better coordinate cross-border responses, on the other hand there is increased societal pressure. People look across borders for information and guidance and want national measures to be subject to peer review by other countries or by international bodies.

The accident in Fukushima also highlighted the need to address the consequences of nuclear accidents in remote parts of the world, even if the exposure to the EU population is negligible and the fraction of imported goods, e.g. food, with potential contamination is so small that it is of no radiological significance. Progress needs to be made in terms of further harmonisation, information exchange and communication.

\section{REFERENCES}

EC (2005) Commission Decision 2005/845/EURATOM of 25 November 2005 concerning the accession of the European Atomic Energy Community to the Convention on Early Notification of a Nuclear Accident (OJ L-314 of 30/11/2005 pages 21-22).

EC (2011) Proposal for a Council Directive laying down basic safety standards for protection against the dangers arising from exposure to ionising radiation [COM(2011)593].

EU (1987a) Council Decision 87/600/EURATOM of 14 December 1987 on Community arrangements for the early exchange of information in the event of a radiological emergency (OJ L-371 of 30/12/87 page 76).

EU (1987b) Council Regulation No 3954/87 of 22 December 1987 laying down maximum permitted levels of radioactive contamination of foodstuffs and of feeding stuffs following a nuclear accident or any other case of radiological emergency (OJ L-371 of 30/12/87 page 11).

EU (1989) Council Directive 89/618/EURATOM of 27 November 1989 on informing the general public about health protection measures to be applied and steps to be taken in the event of a radiological emergency (OJ L-357 of 07/12/89 page 31).

EU (1996) Council Directive 96/29/EURATOM of 13 May 1996 laying down basic safety standards for the health protection of the general public and workers against the dangers of ionizing radiation (OJ L-159 of 29/06/96 page 1).

EU (2009) Council Regulation 1048/2009 of 23 October 2009 amending Regulation (EC) No $733 / 2008$ on the conditions covering imports of 
agricultural products originating in third countries following the accident of the Chernobyl nuclear power station (OJ L-290 of 06/11/2009, page 4).

ICRP Publication 60 (1991) 1990 Recommendations of the International Commission on Radiological Protection, Ann. ICRP 21 (1-3).

ICRP Publication 103 (2007) The 2007 Recommendations of the International Commission on Radiological Protection, Ann. ICRP 37 (2-4).

ICRP Publication 109 (2009a) Application of the Commission's Recommendations for the Protection of People in Emergency Exposure Situations, Ann. ICRP 39 (1).

ICRP Publication 111 (2009b) Application of the Commission's Recommendations to the Protection of People Living in Long-term Contaminated Areas After a Nuclear Accident or a Radiation Emergency, Ann. ICRP 39 (3). 